\title{
COVID-19 and Obesity: Is Bariatric Surgery Protective? Retrospective Analysis on 2145 Patients Undergone Bariatric-Metabolic Surgery from High Volume Center in Italy (Lombardy)
}

\author{
Matteo Uccelli ${ }^{1}$ (D) Giovanni Carlo Cesana ${ }^{1}$ - Stefano Maria De Carli ${ }^{1}$ - Francesca Ciccarese ${ }^{1}$ - Alberto Oldani ${ }^{1}$. \\ Adelinda Angela Giulia Zanoni ${ }^{1}$ - Riccardo Giorgi ${ }^{1} \cdot$ Roberta Villa $^{1}$ - Ayman Ismail ${ }^{1}$ - Simone Targa ${ }^{1}$. \\ Andrea D'Alessio ${ }^{2} \cdot$ Giancarlo Cesana $^{3} \cdot$ Lorenzo Mantovani $^{3} \cdot$ Stefano Olmi $^{1}$
}

Received: 17 September 2020 / Revised: 21 October 2020 / Accepted: 21 October 2020 / Published online: 31 October 2020

(C) Springer Science+Business Media, LLC, part of Springer Nature 2020

\begin{abstract}
Introduction On February 20, 2020, a severe case of pneumonia due to SARS-CoV-2 was diagnosed in northern Italy (Lombardy). Some studies have identified obesity as a risk factor for severe disease in patients with COVID-19. The purpose of this study was to investigate the incidence of SARS-CoV-2 infection and its severity in patients who have undergone bariatric surgery.

Material and Methods During the lockdown period (until May 2020), we contacted operated patients by phone and social networks (e.g., Facebook) to maintain constant contact with them; in addition, we gave the patients a dedicated phone number at which to call us for emergencies. We produced telemedicine and educational videos for obese and bariatric patients, and we submitted a questionnaire to patients who had undergone bariatric surgery in the past.

Results A total of 2145 patients ( 313 male; 1832 female) replied to the questionnaire. Mean presurgical BMI: $44.5 \pm 6.8 \mathrm{~kg} / \mathrm{m}^{2}$. Mean age: $44.0 \pm 10.0$ year. Mean BMI after surgery: $29.3 \pm 5.5 \mathrm{~kg} / \mathrm{m}^{2}(p<0.05)$. From February to May 2020, $8.4 \%$ of patients reported that they suffered from at least one symptom among those identified as related to SARS-CoV-2 infection. Thirteen patients $(0.6 \%)$ tested positive for COVID-19. Six patients $(0.3 \%)$ were admitted to the COVID Department, and 2 patients $(0.1 \%)$ were admitted to the ICU.

Conclusions Although the reported rates of symptoms and fever were high, only $0.6 \%$ of patients tested positive for COVID-19. Among more than 2000 patients who underwent bariatric surgery analyzed in this study, only $0.1 \%$ needed ICU admission.
\end{abstract}

Keywords Obesity surgery $\cdot$ Metabolic surgery $\cdot$ Bariatric surgery, $\cdot$ Obesity $\cdot$ COVID-19 $\cdot$ Italy $\cdot$ Laparoscopy

\section{Introduction}

The spread of coronavirus disease 2019 (COVID-19) has reached - from the beginning of March - the epidemiological criteria to be declared a pandemic (affecting more than 100,000 people in 100 countries) [1]. Only 3 cases of COVID-19 were identified in Italy in the first half of

Supplementary Information The online version contains supplementary material available at https://doi.org/10.1007/s11695-02005085-z.

Matteo Uccelli

matteo.uccelli@gmail.com

Extended author information available on the last page of the article
February 2020, and all involved people who had recently traveled to China. On February 20, 2020, a severe case of pneumonia due to SARS-CoV-2 (severe acute respiratory syndrome-coronavirus 2) was diagnosed in northern Italy's Lombardy region in a man in his thirties who had no history of possible exposure abroad. Within 14 days, many other cases of COVID-19 in the surrounding area were diagnosed, including a substantial number of critically ill patients [2]. Italy, as reported in the data of the Istituto Superiore di Sanità, had 234,111 confirmed cases and 32,354 deaths as of June 3 [3]. The mean age of patients dying from SARS-CoV-2 infection was 79 years. The most common comorbidities diagnosed before SARS-CoV-2 infection were hypertension (69.1\%); type 2 diabetes $(31.7 \%)$; ischemic heart disease (27.5\%); atrial fibrillation (22.0\%); chronic renal failure $(21.1 \%)$; chronic obstructive pulmonary disease $(17.1 \%)$; 
heart failure (16.1\%); and obesity (12.2\%). A total of $60.9 \%$ of the deceased patients had 3 or more comorbidities simultaneously [3]. Based on the number of cases and advanced stage of the disease, it has been hypothesized that COVID-19 has been circulating within the population since January [4]. Although the effects of COVID-19 in patients with obesity have not yet been well described, it has been suggested [5] that there is a need for increased vigilance, prioritization of detection and testing, and aggressive therapy for patients with obesity and COVID-19. Some studies have identified a higher body mass index (BMI) as a risk factor for severe disease in patients with COVID-19 [6, 7]. Patients with obesity have reduced chest wall elastance and lower total respiratory system compliance with a decreased expiratory reserve volume. Difficult airway management, as well as altered physiology in combination with positional gas trapping, is routinely encountered in such patients [8]. In clinical practice, the need for a ventilatory support/ICU bed is one of the main problems in the management of the COVID-19 pandemic $[9,10]$. There are also emerging data indicating that obesity is an independent predictor of intensive care unit (ICU) admission, mechanical ventilation, and death $[6,11,12]$, and in a recent report from a large cohort of COVID-19 patients in New York, obesity was found to be one of the most common associated comorbidities in hospitalized patients $[13,14]$. During the outbreak of the epidemic, our hospital found itself in the Italian epicenter: Lombardy, and in particular the area near the city of Bergamo. We surgeons have been involved, like all physicians, in the management of COVID patients in our hospital, which was transformed into a COVID hospital within a few days. During this period, we treated COVID-19 patients who had undergone bariatric surgery. In particular, we provided treatment for COVID-19 2 ex-bariatric patients operated on at our center and another ex-bariatric patient operated on at another center. We noted in these patients that the response to therapy was good, despite the severity of the infection. We therefore analyzed a significant number of patients to evaluate the spread and the effects of the SARS-CoV-2 infection in a population of patients who had undergone bariatric surgery.

\section{Materials and Methods}

Study Design This study was a cross-sectional retrospective review of patients undergoing bariatric surgery (both primary and redo-surgery) for morbid obesity at the same Bariatric Surgery Centre from December 2002 to March 2020. Starting from March to June in Italy, there were limitations due to the COVID epidemic regarding traveling from city to city and from region to region; in addition, there were limitations in accessing the hospitals and medical practices themselves. To promote continuity in the follow-up of our bariatric patients, we had to shift from in-person to remotely delivered bariatric care by telemedicine, according to the recent Recommendations for Metabolic and Bariatric Surgery During the COVID-19 Pandemic from IFSO [15]. We implemented several methods of remote communication with our patients:

Patients were provided a phone number to call in case of obesity-related questions. A surgeon was available at that number every day from 4 p.m. to 6 p.m.

All patients were usually given the email address of our service at the time of discharge and were encouraged to send emails in case of any concerns. The e-mails were read by surgeons, and an answer was soon sent to each patient, whether the request was for medical advice or for general information.

Obesity-related and bariatric-related groups have been in contact on social networks (e.g., Facebook, "chirurgiapoliclinicosanmarco"), through both our official social page and through self-help groups of obese patients and their associations (e.g., "apslarinascita", "la rinascita ONLUS", "sleeve la rinascita"); we also provided patients with the phone numbers of dieticians and psychologists.

Educational videos were edited and posted by surgeons to these groups, sharing updated information about COVID19 at our hospital, providing general information about eating behavior, and focusing on postoperative signs and symptoms that patients must take into account for contacting doctors.

A survey consisting of 36 questions (Supplementary Information - Attachment 1) was provided to patients electronically, giving the opportunity to respond in compliance with the rules in force in Italy in April. The Italian regulation indicated by the government prevented nonurgent outpatient visits from being carried out and made it impossible to travel from one's own town of residence, except for absolutely necessary and deferred reasons. The questionnaire was administered via social networks and through the mentioned self-help associations. To ensure the correct compilation of the questionnaire, dedicated videos were produced by the promoters of the survey. All patients had morbid obesity before surgery. Data concerning patient demographic variables, age, gender, body mass index (BMI $\mathrm{kg} / \mathrm{m}^{2}$ ), Italian region of residence, comorbid conditions, and type of surgery, were collected. The preoperative characteristics of the population are summarized in Table 1. We have considered the most common clinical presentations of COVID-19 [16-20]; to avoid possible compilation errors by patients, we preferred to omit the symptoms related to loss of taste and smell, as bariatric patients often present these symptoms immediately and long after bariatric surgery $[21,22]$.

Data Collection and Analyses We published the questionnaire and informed the patients on April 21 at noon. The questionnaire was available for 9 days until April 30 at midnight. Each operated patient could complete the questionnaire only once, 
answering all the questions anonymously. Continuous demographic variables are expressed as the mean \pm standard deviation and range. Categorical variables and complications are reported as numbers and percentages. Data were processed by XLStat to perform statistical analyses. Statistical significance was predetermined as $p<0.05$.

\section{Results}

\section{A Total of 2145 Patients Correctly Completed the Questionnaire}

Preoperative Data Patient characteristics and preoperative assessments are summarized in Table 1. All patients underwent elective bariatric surgery from December 2002 to March 2020. The mean presurgical BMI was $44.5 \pm 6.8 \mathrm{~kg} /$ $\mathrm{m}^{2}$ (range: $30.0-86.3$ ), and the mean age was $44.0 \pm 10.0$ years (range: 18-70). The patients were from all over Italy, with a greater proportion of patients coming from the following locations: southern Italy: Puglia (882-41.1\%) and Campania (106-4.9\%); northern Italy: Lombardy (390-18.2\%) and Piemonte (146-6.8\%); and central Italy: Lazio (107-5.0\%). The most performed operation was laparoscopic sleeve gastrectomy (LSG), 1768 cases (82.4\%).
Comorbidities and follow-up are summarized in Table 1. With an average follow-up of $22.9 \pm 20.2$ months (range: 0.5 211.7 ), we found an average BMI of $29.3 \pm 5.5 \mathrm{~kg} / \mathrm{m} 2$ $(p<0.05)$. Reductions in the number of comorbidities were almost all statistically significant (Graph 1 ).

COVID-19 A total of 231 (10.8\%) patients were prescribed home isolation following the development of symptoms or contact with COVID-19 patients (fiduciary home quarantine). A total of $4.6 \%$ (99) of the patients reported having had a fever above $37.5^{\circ} \mathrm{C}$. A total of 153 patients $(7.1 \%)$ reported coughing, respiratory symptoms, or dyspnea. In total, 181 patients $(8.4 \%)$ reported having had at least one symptom among those identified as related to SARS-CoV-2 infection. Nevertheless, testing for COVID-19 was performed only in 26 cases $(1.2 \%)$. Thirteen patients $(0.6 \%)$ tested positive for COVID-19 (Table 2), nine in the northern section of the country, where the epidemic has been more intense, and four in the south-central region. These COVID-19-positive patients were initially treated at home in 8 cases $(0.4 \%)$. The average duration of home treatment was $23.3 \pm 13.6$ days. Six patients $(0.3 \%)$ were admitted to the COVID Department. The average length of hospitalization at COVID Hospital was $27.8 \pm$ 10.5 days. In two cases $(0.1 \%)$, patients were admitted to intensive care. Both of these patients were intubated with invasive mechanical ventilation. The average duration of inva-
Table 1 Patient characteristics, type of bariatric surgery, and follow-up

\begin{tabular}{|c|c|c|c|}
\hline \multicolumn{4}{|c|}{ Demographics (number of patients: 2145 ) } \\
\hline \multicolumn{2}{|l|}{$\mathrm{M} / \mathrm{F}, n(\%)$} & \multicolumn{2}{|l|}{$313(14.6 \%) / 1832(85.4 \%)$} \\
\hline \multicolumn{2}{|l|}{ Age (years), mean $\pm \mathrm{SD}$ (range) } & \multicolumn{2}{|l|}{$44.0 \pm 10.0(18-70)$} \\
\hline \multicolumn{2}{|c|}{ BMI PRE $\left(\mathrm{kg} / \mathrm{m}^{2}\right)$, mean \pm SD (range) } & \multicolumn{2}{|l|}{$44.5 \pm 6.8(30.0-86.3)$} \\
\hline \multicolumn{2}{|c|}{ Follow-up (months), mean $\pm \mathrm{SD}$ (range) } & \multicolumn{2}{|l|}{$22.9 \pm 20.2(0.5-211.7)$} \\
\hline \multicolumn{4}{|l|}{ Surgery (number of patients: 2145 ) } \\
\hline \multicolumn{2}{|l|}{ LSG, $n(\%)$} & \multicolumn{2}{|l|}{$1768(82.4 \%)$} \\
\hline \multicolumn{2}{|c|}{ Laparoscopic modified sleeve gastrectomy, $n(\%)$} & \multicolumn{2}{|l|}{$90(4.2 \%)$} \\
\hline \multicolumn{2}{|l|}{ Laparoscopic removal of $\mathrm{AGB}, n(\%)$} & \multicolumn{2}{|l|}{$10(0.5 \%)$} \\
\hline \multicolumn{2}{|l|}{ Laparoscopic OAGB, $n(\%)$} & \multicolumn{2}{|l|}{$110(5.2 \%)$} \\
\hline \multicolumn{2}{|c|}{ Laparoscopic removal of AGB and LSG, $n(\%)$} & \multicolumn{2}{|l|}{$13(0.6 \%)$} \\
\hline \multicolumn{2}{|l|}{ Re-do surgery, $n(\%)$} & \multicolumn{2}{|l|}{$35(1.6 \%)$} \\
\hline \multicolumn{2}{|l|}{ Other, $n(\%)$} & \multicolumn{2}{|l|}{$119(5.5 \%)$} \\
\hline \multicolumn{4}{|l|}{ Comorbidities and follow-up } \\
\hline & PRE (2145) & POST (2145) & $p$ \\
\hline Weight $(\mathrm{kg})$, mean $\pm \mathrm{SD}$ (range) & $121.2 \pm 22.9(67.0-250.0)$ & $79.7 \pm 16.6(42.3-166.7)$ & $p<0.05$ \\
\hline BMI $\left(\mathrm{kg} / \mathrm{m}^{2}\right)$, mean $\pm \mathrm{SD}$ (range) & $44.5 \pm 6.8(30.0-86.3)$ & $29.3 \pm 5.5(16.5-55.8)$ & $p<0.05$ \\
\hline Hypertension, $n(\%)$ & $759(35.4 \%)$ & $225(10.5 \%)$ & $p<0.05$ \\
\hline Diabetes mellitus, $n(\%)$ & $267(12.5 \%)$ & $33(1.5 \%)$ & $p<0.05$ \\
\hline GERD, $n(\%)$ & $859(40.1 \%)$ & $492(22.9 \%)$ & $p<0.05$ \\
\hline Sleep apnea syndrome, $n(\%)$ & $603(28.1 \%)$ & $54(2.5 \%)$ & $p<0.05$ \\
\hline No comorbidities, $n(\%)$ & $662(30.9 \%)$ & $1456(67.9 \%)$ & $p<0.05$ \\
\hline
\end{tabular}

$M$ male, $F$ female, $S D$ standard deviation, $B M I$ body mass index, $L S G$ laparoscopic sleeve gastrectomy, $A G B$ adjustable gastric banding, $O A G B$ one-anastomosis gastric bypass, GERD gastroesophageal reflux disease 
Table 2 COVID-19:

characteristics of patients who developed COVID-19 infection

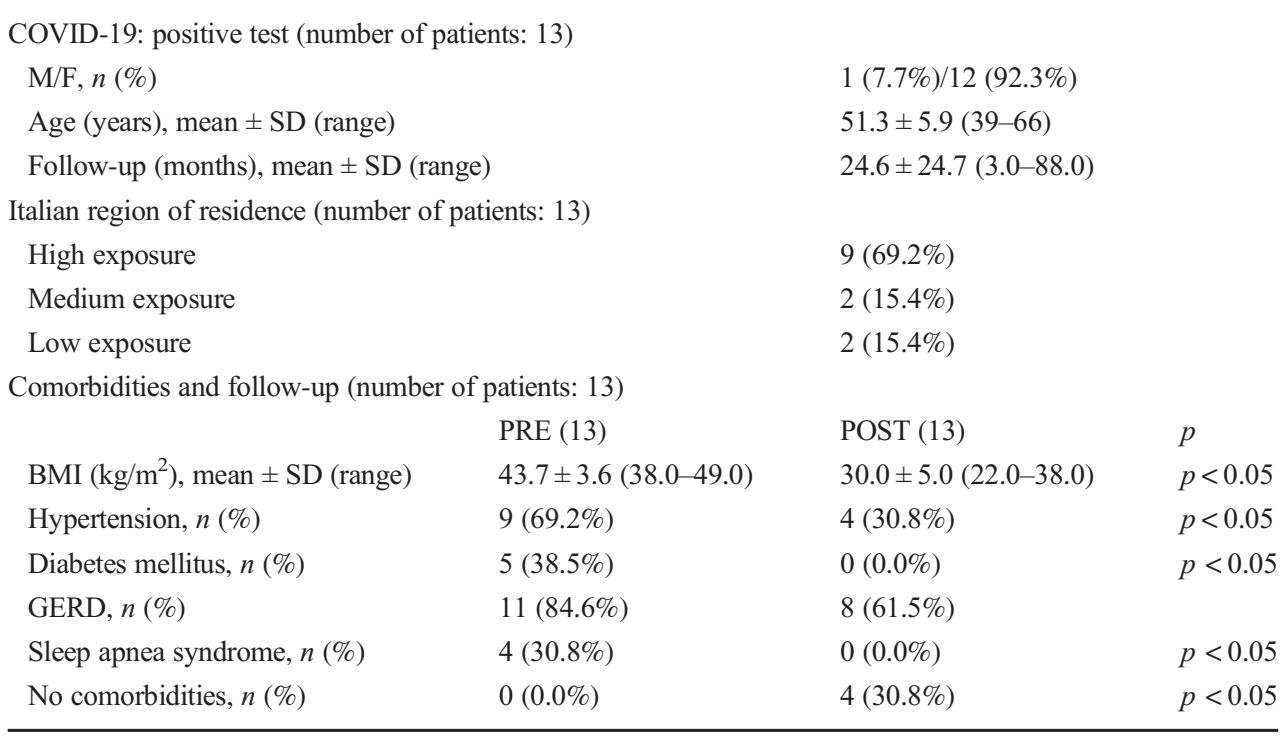

$S D$ standard deviation, $L S G$ : laparoscopic sleeve gastrectomy, $O A G B$ one-anastomosis gastric bypass, $B M I$ body mass index, GERD gastroesophageal reflux disease sive mechanical ventilation was $8.5 \pm 3.5$ days. At the end of the therapy period, $9(0.4 \%)$ patients had a negative COVID19 test. At the end of the investigation, 4 patients were still positive for COVID-19.

\section{Discussion}

Coronavirus disease-2019 (COVID-19) is an infectious disease caused by the recently discovered coronavirus SARS-CoV-2 [9]. The first case of COVID-19 was reported to the World Health Organization (WHO) by Chinese authorities on December 31, 2019, as a result of a patient experiencing pneumonia in Wuhan City, Hubei Province. Following a rapid spread in China, new outbreaks occurred first in northern Italy and then in several European countries. The spread in Italy has been intense since January [4], and individuals with obesity, particularly its complications, such as diabetes and hypertension, might be more liable to develop serious illness, requiring hospital admission and invasive ventilation [11].
Graph 1 Follow-up: comorbidities, ${ }^{*} p<0.05$. GERD, gastroesophageal reflux disease

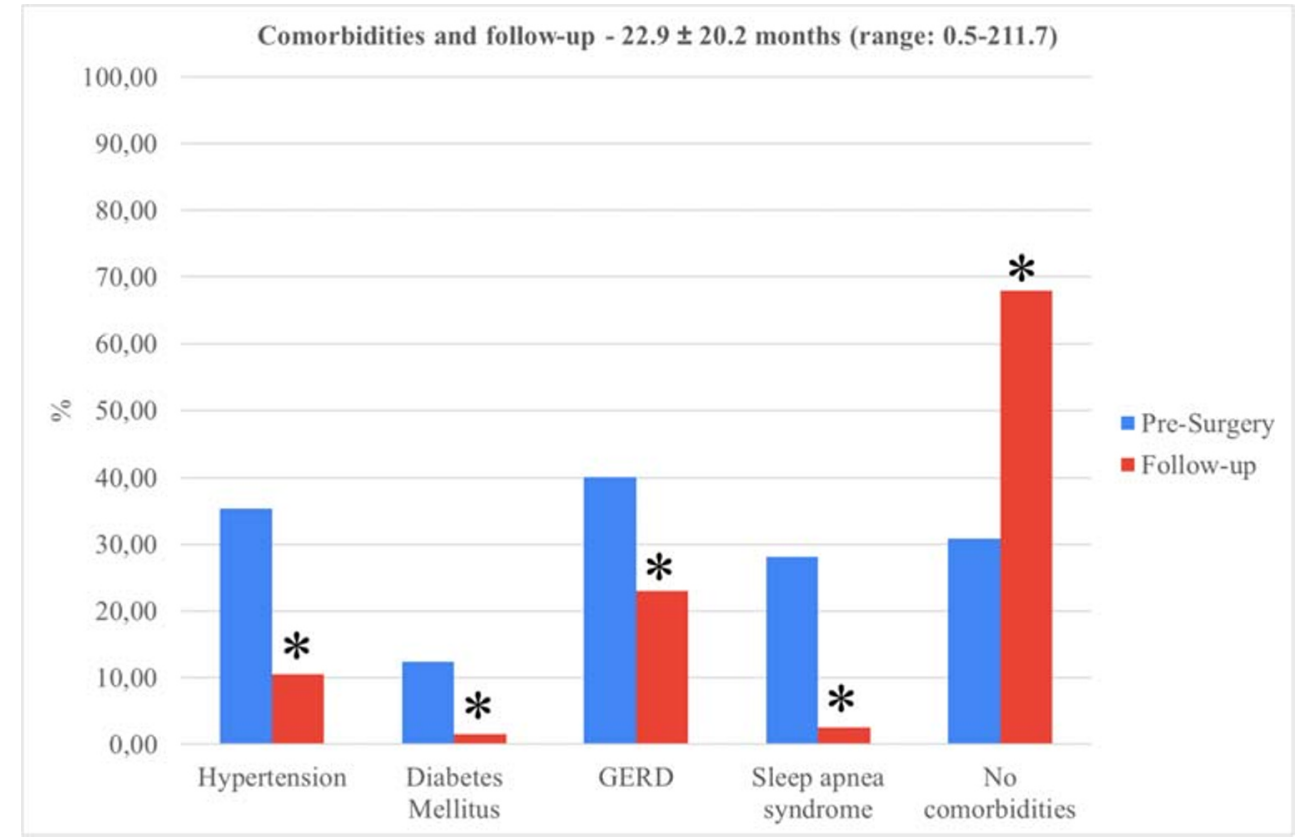


From a strictly bariatric point of view, our patients reported weight loss and remission of comorbidities that fall within the normalcy [23]. A total of $8.4 \%$ of patients reported at least one COVID-19-related symptom. However, almost all patients (98.8\%) did not undergo any COVID-19 testing. Although this report highlights a possible underestimation of the spread of the infection in Italy, few patients required home or hospital treatment, and even fewer $(0.1 \%)$ developed severe forms requiring intensive care. These data confirm what we noticed during the period of assistance to postbariatric COVID-19 patients [24], with good response and resolution of pneumonia.

Hajifathalian et al. [14] reported that obesity was associated with increased risk of ICU admission or death whereas being underweight was not. The comparison, given the small size of our sample of patients who tested positive for the COVID-19 test, is partial. However, in our patients, there were positive results for the infection (13 patients), with less than half hospitalized. The ICU admission rate in our case series (only two patients) was also lower than that in the literature data (17.9-33.21\%) $[14,25]$. Stratifying by BMI, the literature data report ICU admission rates greater than $30 \%$ for patients with BMI $>30$ [14]. Therefore, our data are encouraging, considering that these patients were obese: bariatric surgery and the consequent weight loss seem to significantly lower the risk of serious consequences due to COVID infection. Bariatric surgery, therefore, can be considered a protective factor with respect to the onset of severe respiratory disease resulting from SARS-CoV-2 infection and probably other respiratory diseases. Furthermore, considering the changes in quality of life in the patient undergoing bariatric surgery [26], the weight-loss patient becomes a socially active individual who is more exposed to contacts with COVID-19-positive individuals. Especially in the first phase of the pandemic in Italy, when no social restriction measures were adopted, COVID-19 circulated freely [4]. Our large population of potentially exposed postbariatric patients did not show a higher incidence than the general population, especially in forms of more serious infections [27-29].

A strength of this study is the population size (over 2000 patients). Furthermore, another strong point is the geographical distribution of the patients, who - although operated on and followed by a single bariatric center - came from areas all over Italy with different diffusions of COVID-19 in the January-May period. As already pointed out, the analyzed population is socially active, as often happens to ex-obese patients currently losing weight. The main limitations of the study were (1) the unavailability of a comparable control group of obese patients not undergoing bariatric surgery and (2) the use of a survey performed with a questionnaire without the possibility of a direct clinical and diagnostic evaluation.

\section{Conclusion}

Although the reported rate of symptoms was high, only $0.6 \%$ of patients tested positive for COVID-19. Out of more than 2000 patients analyzed in this study who underwent bariatric surgery, only 2 patients $(0.1 \%)$ needed ICU admission. Bariatric surgery, therefore, can be considered a protective factor with respect to the onset of severe respiratory disease resulting from infection with SARS-CoV-2.

\section{Compliance with Ethical Standards}

Conflict of Interest The authors declare that they have no conflict of interest.

Ethical Approval Study did not require approval from the ethics committee and for this type of study formal consent is not required.

Human and Animal Rights and Informed Consent This article does not contain any studies with human participants or animals performed by any of the authors. Informed consent was obtained from all individual participants included in the study.

\section{References}

1. Callaway E. Time to use the p-word? Coronavirus enter dangerous new phase. Nature. 2020;579:12.

2. Grasselli G, Pesenti A, Cecconi M. Critical Care Utilization for the COVID-19 Outbreak in Lombardy, Italy: early experience and forecast during an emergency response [published online ahead of print, 2020 Mar 13]. JAMA. 2020; https://doi.org/10.1001/jama.2020. 4031.

3. Task force COVID-19 del Dipartimento Malattie Infettive e Servizio di Informatica, Istituto Superiore di Sanità. Epidemia COVID-19, Aggiornamento nazionale: 5 giugno 2020. https:// www.epicentro.iss.it/coronavirus/bollettino/Bollettinosorveglianza-integrata-COVID-19 3-giugno-2020.pdf

4. Onder G, Rezza G, Brusaferro S. Case-fatality rate and characteristics of patients dying in relation to COVID-19 in Italy. JAMA. 2020; https://doi.org/10.1001/jama.2020.4683.

5. Dietz W, Santos-Burgoa C. Obesity and its implications for COVID-19 mortality. Obesity (Silver Spring). 2020; https://doi. org/10.1002/oby.22818.

6. Peng YD, Meng K, Guan HQ, et al. Clinical characteristics and outcomes of 112 cardiovascular disease patients infected by 2019 nCoV. Zhonghua Xin Xue Guan Bing Za Zhi. 2020;48(0):E004. Chinese. https://doi.org/10.3760/cma.j.cn112148-2020022000105.

7. Wu J, Li W, Shi X, et al. Early antiviral treatment contributes to alleviate the severity and improve the prognosis of patients with novel coronavirus disease (COVID-19). J Intern Med. 2020;288: 128-38. https://doi.org/10.1111/joim.13063.

8. Pelosi P, Gregoretti C. Perioperative management of obese patients. Best Pract Res Clin Anaesthesiol. 2010;24(2):211-25. Review

9. Gattinoni L, Chiumello D, Rossi S. COVID-19 pneumonia: ARDS or not? Crit Care. 2020;24(1):154. https://doi.org/10.1186/s13054020-02880-z.

10. Grasselli G, Zangrillo A, Zanella A, et al. Baseline characteristics and outcomes of 1591 patients infected with SARS-CoV-2 
admitted to ICUs of the Lombardy region, Italy. JAMA. 2020;323(16):1574-81. https://doi.org/10.1001/jama.2020.5394.

11. Simonnet A, Chetboun M, Poissy J, et al. High prevalence of obesity in severe acute respiratory syndrome coronavirus-2 (SARSCoV-2) requiring invasive mechanical ventilation. Obesity (Silver Spring). 2020; https://doi.org/10.1002/oby.22831, https://doi.org/ 10.1002/oby.22831.

12. Lighter J, Phillips M, Hochman S, Sterling S, Johnson D, et al. Obesity in Patients Younger Than 60 Years Is a Risk Factor for COVID-19 Hospital Admission. Clin Infect Dis. 2020 Jul 28;71(15):896-897. https://doi.org/10.1093/cid/ciaa415.

13. Richardson S, Hirsch JS, Narasimhan M, et al. Presenting characteristics, comorbidities, and outcomes among 5700 patients hospitalized with COVID-19 in the New York City area. JAMA. 2020;323(20):2052-9. https://doi.org/10.1001/jama.2020.6775. Erratum in: doi: 10.1001/jama.2020.7681

14. Hajifathalian K, Kumar S, Newberry C, et al. Obesity is associated with worse outcomes in COVID-19: analysis of early data from New York City. Obesity (Silver Spring). 2020; https://doi.org/10. 1002/oby.22923.

15. Yang W, Wang C, Shikora S, et al. Recommendations for metabolic and bariatric surgery during the COVID-19 pandemic from IFSO. Obes Surg. 2020;30(6):2071-3. https://doi.org/10.1007/ s11695-020-04578-1.

16. COVID-19 Investigation Team. Clinical and virologic characteristics of the first 12 patients with coronavirus disease 2019 (COVID19) in the United States. Nat Med. 2020; https://doi.org/10.1038/ s41591-020-0877-5.

17. Lovato A, de Filippis C. Clinical Presentation of COVID-19: A Systematic Review Focusing on Upper Airway Symptoms. Ear Nose Throat J. 2020 Nov;99(9):569-576.https://doi.org/10.1177/ 0145561320920762 .

18. Zhang JJ, Dong X, Cao YY, et al. Clinical characteristics of 140 patients infected with SARS-CoV-2 in Wuhan, China. Allergy. 2020;75:1730-41. https://doi.org/10.1111/all.14238.

19. Wang Z, Yang B, Li Q, Wen L, Zhang R. Clinical Features of 69 Cases With Coronavirus Disease 2019 in Wuhan, China. Clin Infect Dis. 2020 Jul 28;71(15):769-777. https://doi.org/10.1093/ $\mathrm{cid} / \mathrm{ciaa} 272$.

20. Lechien JR, Chiesa-Estomba CM, De Siati DR, et al. Olfactory and gustatory dysfunctions as a clinical presentation of mild-tomoderate forms of the coronavirus disease (COVID-19): a multicenter European study. Eur Arch Otorhinolaryngol. 2020;6:1-11. https://doi.org/10.1007/s00405-020-05965-1.
21. Shoar S, Naderan M, Shoar N, et al. Alteration pattern of taste perception after bariatric surgery: a systematic review of four taste domains. Obes Surg. 2019;29(5):1542-50. https://doi.org/10.1007/ s11695-019-03730-w.

22. Makaronidis JM, Neilson S, Cheung WH, et al. Reported appetite, taste and smell changes following Roux-en-Y gastric bypass and sleeve gastrectomy: effect of gender, type 2 diabetes and relationship to post-operative weight loss. Appetite. 2016;107:93-105. https://doi.org/10.1016/j.appet.2016.07.029.

23. Shoar S, Saber AA. Long-term and midterm outcomes of laparoscopic sleeve gastrectomy versus Roux-en-Y gastric bypass: a systematic review and meta-analysis of comparative studies. Surg Obes Relat Dis. 2017;13(2):170-80. https://doi.org/10.1016/j. soard.2016.08.011.

24. Uccelli M, Cesana GC, Ciccarese F, Oldani A, Zanoni AAG, De Carli SM, et al. "COVID-19 and Obesity: Postoperative Risk in Patients Who Have Undergone Bariatric Surgery. Preliminary Report from High Volume Center in Italy (Lombardy)". Obes Surg. 2020 Jun 27:1-4. https://doi.org/10.1007/s11695-02004792-x.

25. Argenziano MG, Bruce SL, Slater CL, et al. Characterization and clinical course of 1000 patients with coronavirus disease 2019 in New York: retrospective case series. BMJ. 2020;369:m1996. https://doi.org/10.1136/bmj.m1996.

26. Lindekilde N, Gladstone BP, Lübeck M, et al. The impact of bariatric surgery on quality of life: a systematic review and meta-analysis. Obes Rev. 2015;16(8):639-51. https://doi.org/10.1111/obr. 12294.

27. Signorelli C, Scognamiglio T, Odone A. COVID-19 in Italy: impact of containment measures and prevalence estimates of infection in the general population. Acta Biomed. 2020;91(3-S):175-9. https://doi.org/10.23750/abm.v91i3-S.9511.

28. Conti S, Ferrara P, Mazzaglia G, et al. Magnitude and time-course of excess mortality during COVID-19 outbreak: population-based empirical evidence from highly impacted provinces in northern Italy. ERJ Open Res. (in press). 2020; https://doi.org/10.1101/ 2020.07.10.20150565.

29. Tuite AR, Ng V, Rees E, et al. Estimation of COVID-19 outbreak size in Italy. Lancet Infect Dis. 2020;20(5):537. https://doi.org/10. 1016/S1473-3099(20)30227-9.

Publisher's Note Springer Nature remains neutral with regard to jurisdictional claims in published maps and institutional affiliations.

\section{Affiliations}

\section{Matteo Uccelli ${ }^{1}$ (D) Giovanni Carlo Cesana ${ }^{1}$ - Stefano Maria De Carli ${ }^{1}$. Francesca Ciccarese ${ }^{1} \cdot$ Alberto Oldani $^{1}$. Adelinda Angela Giulia Zanoni ${ }^{1}$ - Riccardo Giorgi ${ }^{1}$ - Roberta Villa ${ }^{1}$ - Ayman Ismail ${ }^{1}$. Simone Targa ${ }^{1}$. Andrea D'Alessio ${ }^{2} \cdot$ Giancarlo Cesana $^{3} \cdot$ Lorenzo Mantovani $^{3} \cdot$ Stefano Olmi $^{1}$}

Giovanni Carlo Cesana

giovanni.cesana@gmail.com

Stefano Maria De Carli

stefanodecarli@yahoo.com

Francesca Ciccarese

fra.ciccarese@gmail.com

Alberto Oldani

alberto.oldani@libero.it
Adelinda Angela Giulia Zanoni

adelindazanoni@gmail.com

Riccardo Giorgi

riccardogio@yahoo.it

Roberta Villa

robe.villa@tiscali.it

Ayman Ismail

aymanismai12579@gmail.com 
Simone Targa

simotarga87@gmail.com

Andrea D'Alessio

dr.dalessio@gmail.com

Giancarlo Cesana

giancarlo.cesana@unimib.it

1 General and Oncologic Surgery Department - Centre of Bariatric Surgery, San Marco Hospital GSD, Corso Europa, 7,

24040 Zingonia, BG, Italy
Lorenzo Mantovani

lorenzo.mantovani@unimib.it

Stefano Olmi

stefano.olmi@gmail.com

2 Internal Medicine and COVID Medical Department, San Marco Hospital GSD, Zingonia, BG, Italy

3 Research Center on Public Health, University of Milano Bicocca, Milan, Italy 